\title{
Children's paired associate learning of verbal and pictorial material
}

\author{
ROBERT E. KLEIN ${ }^{2}$, GORDON A. HALE, LEON K. MILLER, AND HAROLD W. STEVENSON
} UNIVERSITY OF MINNESOTA

Third and fifth grade Ss were presented paired-associate tasks which differed in the response elements used: concrete and abstract words and concrete and abstract forms. $A$ higher level of performance was found with the concrete than with the abstract materials. A superiority of performance with concrete forms over concrete words was not found. Significant developmental differences in performance occurred for the verbal tasks, and there were significant sex differences for the tasks employing concrete materials.

A recent study by Paivio \& Yuille (1966) indicated that when abstract and concrete words were used as either stimulus or response elements, children's learning and recall were better when the elements were concrete words than when they were abstract words. The present study is a further investigation of this effect, and is concerned with possible differences in children's paired-associate learning at two age levels as a function of abstract and concrete verbal, as well as abstract and concrete pictorial response elements. The concrete words had a direct physical referent and the abstract words represented concepts that could not be readily represented pictorially. The concrete forms were drawings of the objects represented by the concrete words, while the abstract forms were Japanese characters for which no verbal label was readily avallable.

Subjects

The Ss were 87 boys and 126 girls in third grade and 105 boys and 112 girls in fifth grade enrolled in 16 classrooms in four elementary schools in middle class areas of Minneapolis and St. Paul. The average CA of the third grade $\mathrm{Ss}$ was 8.4 years $(S D=.4)$ and of the flfth grade $\mathrm{Sa}, 10.4$ years $(\mathrm{SD}=.4)$. The average $\mathrm{IQ}$ (Lorge-Thorndike Verbal IQ) for the third grade Ss was 107.4 ( $\mathrm{SD}=12.5$ ) and for the fifth grade Ss, 108.7 ( $\mathrm{SD}=13.1$ ).

Tasks

Four palred-associate tasks were used in this study, each consisting of six stimulus-response pairs. The stimulus elements were nonsense syllables chosen from Archer's (1960) CVC trigrams with association value ratings between 83 and 86 percent. No two nonsense syllables had the same initial or final consonant. Different stimulus elements were used in each of the four tasks. For each task, two films were constructed with identical stimulus and response elements but different stimulus-response pairings. The response element designated as correct for each stimulus element was determined at random, except for the restriction that no trigram had the same initial letter as the response element designated as correct.
A different class of response elements was used in each task. In Concrete Words the response elements were nouns that could be represented pictorially (e.g., bird, flower, chair), while in Abstract Words they were words representing abstract concepts (e.g., health, wish, joy). The words used in both tasks were selected at random from the Thorndike-Lorge (1944) list of words that occur 100 or more times per million. In Concrete Forms the response elements were line drawings of the objects represented by the nouns in Concrete Words, and in Abstract Forms the response elements were Japanese characters containing five strokes in different configurations.

The response booklet for each task contained eight pages. The six stimulus elements were arranged in a column along the left side of each page, and all stx of the response elements appeared in a row to the right of each stimulus element. The linear arrangement of the response elements and the order of stimulus elements was counterbalanced across the successive pages.

The task was explained by an announcer on the fulm. The Ss were told that their job was to remember which made-up words and real words (plctures) went together. They were told they first would see all the pairs and then they would respond in their booklets. The first stimulus element appeared for $3 \mathrm{sec}$, followed by a $3 \mathrm{sec}$ presentation of the stimulus and response elements. The presentation of successive pairs was separated by a $2 \mathrm{sec}$ interval. After this procedure had been followed for the six pairs, the first page of the booklet appeared on the screen and the Ss were told to draw a circle around the real word (picture) they thought was correct for each made-up word. The Ss were closely monitored so that it was impossible for them to refer to answers made on previous sheets of the booklet.

The films were presented to intact classrooms. Each of the eight films was assigned randomly to one of the classrooms at each grade, except that only one classroom at each grade was shown the Concrete Words film and three were shown the Abstract Words films. Results

The mean numbers of correct responses for each task are presented in Table 1 for each grade. The level of performance was higher with concrete than with abstract response elements, both when they were forms $(t=4.64, d f=217, p<.01)$ and when they were words $(t=1.91, d f=209, p<.05$, one-tailed test). There was no significant difference in the average level of performance between Concrete Words and Concrete Forms at either grade $(p>.10)$. The overall level of 
Table 1 Mean correct responses on paired-associate tasks Task

\begin{tabular}{cccccc} 
Grade & Concr. Words & \multicolumn{1}{c}{ Abstr. Words } & Concr. Forms & Abstr. Forms \\
\hline 3 & M & 29.09 & 25.14 & 33.41 & 27.70 \\
& SD & 9.89 & 11.30 & 12.30 & 9.11 \\
& N & 27 & 79 & 55 & 52 \\
5 & M & 35.07 & 33.08 & 36.48 & 29.21 \\
& SD & 9.68 & 10.61 & 9.80 & 9.65 \\
& N & 29 & 76 & 58 & 54 \\
\hline
\end{tabular}

performance was higher at grade 5 than at grade 3 on all tasks, but the difference was significant only for Concrete Words $(t=2.28, d f=54, p<.05)$, and Abstract Words $(t=4.51, d f=153, p<.001)$. The mean number of correct responses for girls was higher than that for boys for Concrete Forms at both grades ( $t \geq 2.48$, df $\geq 53, p<.05$ ) and for Concrete Words at grade 5 $(t=2.24, \mathrm{df}=27, \mathrm{p}<.05)$.

\section{Discussion}

The results confirm and extend those of Paivio \& Yuille (1966), for the superiority of performance with concrete materials compared to abstract materials was evident for both words and forms. Variation in the response elements was sufficient to produce these effects even though, as Paivio and Yuille found, variation in stimulus elements may result in greater differences. In many studies of cognitive development children have been found to deal more effectively with concrete materials than with abstract materials, thus these results for paired-associate learning are in line with such findings.

The highest levels of performance occurred with concrete forms. The failure to find a significant difference between the groups given concrete forms and concrete words is comparable to the results of similar studies that have been conducted with adults (e.g., Paivio \& Yarmey, 1966). It is possible that, since the forms and words represented very common objects, both rapidly became functionally similar in the types of mediational processes they elicited.

It is of interest that significant developmental differences were found only for verbal materials. Although the young Ss were able to read the words, they were less effective than were the older Ss in using the words appropriately in the formation of associations. Thus, there appears to be a greater increase during this age period in the ability to differentiate verbal than pictorial materials.

\section{References}

ARCHER, E. J. Re-evaluation of the meaningfulness of all possible CVC trigrams. Psychol. Monogr., 1960, 74, No. 10.

PAIVIO, A., \& YARMEY, A. D. Pictures versus words as stimuli and responses in paired-associate learning. Psychon. Sci, 1966, 5, 235-236.

PAIVIO, A., \& YUILLE, J. C. Word abstractness and meaningfulness, and paired-associate learning in children. J. exp. child Psychol., 1966, 4, 81-89.

THORNDIKE, E. L., \& LORGE, I. The teacher's word book of 30,000 words. New York: Bureau of Publications, Teacher's College, 1944.

\section{Notes}

1. This study was supported by grant $\mathbf{M - 3 5 1 9}$ from the National Institute of Mental Health. The writers express their appreciation to Gary M. Olson, Daniel Bibelheimer, Miye Cohen, and the many other persons who assisted us in this project.

2. Now at Instituto de Nutricion de Centro America y Panama, Ciudad, Guatemala. 